Abstract

Purpose - This paper outlines some of the social, cultural, political and economic conditions in which four of only seven women who have become Rectors of public universities in Vietnam. Their experiences are described with a focus on the context of Vietnam in order to focus more clearly on non-western starting points for theory about career development in higher education in Vietnam and other non-western settings.

Design/methodology/approach - A combination of historical and personal accounts is used to situate the points of view of Vietnamese women and to argue for the processes of becoming a Rector as an important and significant point for understanding how women gain entry to high-status and previously all-male domains.

Findings - Findings demonstrate that while family/career relationships are crucial in reporting these women's experiences, too much emphasis on these aspects can divert attention away from the conditions historically blocking the initial journey into high-status parts of an organisation. These processes in which the is initiated cannot be fully contained within western theory and literature.

Research limitations/implications - The sample size of four is a limitation and the interviews do not extend to colleagues and family members, but the four women represent over half of the total population of Vietnamese women Rectors. On balance though, the research contains implicit material that would be of interest to others in the area to build on with further case studies either in Vietnam or other Asian countries.

Practical implications - The experiences of the women Rectors could provide examples lacking in Vietnamese society and in literature there. The experiences could be a role-model for other women's pursuits of careers in Vietnam.

Originality/value - The paper is the first of its type on women's careers in Vietnam and contributes to the development of further study individual women, for women's groups and academic debate in Vietnamese society. The paper could provide some discussion on where strategies might be most appropriately be devised and implement to counter loss of small gains made in women's careers and within the values in Vietnamese society.

Social Implications - The paper contributes in identifying processes of becoming and their reliance on social conditions from the personal powers can be generated. For this framework to be effective, factors such as management style adopted when women are "at the top" must be separated from conditions that have made the "journeys to the top" possible in the first place.

Keywords Women, Careers, Vietnam, Career development, Non-western theory development Paper type Research paper 


\section{Journeys to the Top: Women University Rectors in Vietnam}

\section{Introduction}

In this paper we describe some experiences and key points in the career trajectories of four of seven of the only women to become Rectors of public universities in Vietnam. We place the issue in the historical contexts of Vietnamese society where, to propose women can rise above being second-in-command to men in any aspect of family and working life, is to question engrained social norms about the place of women within the social order. While our purpose is to present their journeys as much as possible within the context of Vietnam, it is important, of course, to seek equivalences or partial similarities with women seemingly in these same management or leadership category in other countries. The intention in our research and writing has not been to generalise, test theory or build a model about women who make it to a top-level managerial levels. Instead we use feminist standpoint epistemology as a method, as a base point for seeing relations within Vietnamese society, and in turn, the experiences of women in its higher education system. While it is significant to record how such a small number of women have reached this level, placing too much emphasis on similarities may override the exploration of the differences in how these women become Rectors. With this in mind, our study is presented as a first step towards seeing broader likenesses and differences.

The rest of the paper is organized as follows. We begin with a short summary of the position of women in Vietnam and in higher education. From this we briefly explore some problems inherent comparing Asian and western models of career planning. The study and methods used are then described which is followed by three factors influencing the advancement of women found in our study: collective standpoints, Confucianism and the economic reforms 
of the Doi Moi. The processes of becoming and being a female Rector are then analysed with conclusions being made about coexisting in a male context and implications for theory.

\section{The problem of women's career advancement in Vietnam}

Vietnamese women, as in other countries, are under-represented at senior ranks of large scale, prestigious organisations. Statistical, comparable evidence of gender inequity common in country profile reports (e.g. from The World Bank) carries into the broader literature. Pham Hanh Sam (2011) from the Women's Union of Viet Nam provides an example. She recognises that while women in Vietnam, currently "make up $47 \%$ of the labor force," and while there has been "a remarkable" increase in numbers into management positions in State and Government offices, social organizations and businesses, more women than before are Vice State Presidents and Chairs of The National Assembly and Political Bureau members, "the percentages of woman in leadership and management positions are not steady. They are "unstable and decreasing." Something similar can be said of other Asian countries. In 2006, there were only four women Presidents in the total of seventy three national universities in mainland China. Hong Kong has had only one woman Vice-Chancellor (Tsang \& Zhang, 2006). What does this say about explaining the circumstances in which Vietnam has only ever come to appoint seven women Rectors across a system of over fifty public universities? A lack of literature about this and other topics about women's careers means that metaphors such as a "glass ceiling" and work-life conflict, low career aspirations, workplace stereotypes and unwelcoming work cultures shaped around masculine values form a basis for Asian literature (Vo and Strachan, 2008). But there are differences in how these obstacles are generated by local history and culture and the impact on the prospects of senior women leaders in Asian settings (Jogulu and Wood, 2011; Luke, 2001). How this problem is played out in the context of Vietnam is the topic of this paper. 
That no women had been Rectors in Vietnamese universities until recent times implies this is a restricted area for women. According to statistics of the Ministry of Education and Training (MOET) while women make up two thirds of educational professionals in Vietnam, the heads of educational institutions are usually men. Recent statistics show that women comprise around 15 percent of Rectors, Deputy-Rectors and Faculty Deans, but that there were no women in any of these positions in ten of the total of the 53 public universities open in 2004 (Mai, 2007). No qualitative research exists to explain what in the experiences of women leads a few to prevail and prevents others from becoming senior managers in Vietnamese higher education. This possibly relates to an absence of qualitative forms of research in university faculties. To this end, the problem of situating the journeys of four women university Rectors is to provide a qualitative description set within Vietnamese society as a base on which similarities and differences can be made.

\section{Exploring Similarity and Difference}

Cheung and Halpern (2010) propose a "step by step" model through women "at the top" have become successful leaders. In comparing the experiences of women in Hong Kong and the US, they bracket out differences due to culture and context and concentrate on a core element, a shared "culture of gender." Thus it is important here to see how this culture is built on as women cope with a shared problem of balancing family care responsibilities as they rise to the top of their professions. Their model represents a three stage psychological process for showing women's career transitions. The model begins (i) with early parental encouragement, career success and (ii) to a stage of gaining self-efficacy and motivation in starting a family and advancing a career and (iii) to a final stage of securing organizational and family support for a transformative leadership style. The model does, as they contend, give a picture of the personal attributes of leaders that can steer successful career paths. It 
also includes psychological factors that would incorporate women across "diverse global contexts." Indeed, Yáñez and Moreno (2008) explain career change in loosely coupled higher education organisations along these lines. But from our research, it is problematic as to how the model would explain entry to the CEO, or "O level" type positions Cheung and Halpern mention as being still out of reach for all but a small percentage of women.

Vietnam, for example, is a one party state, controlled by the Communist Party of Vietnam [CPV]. In general, selection criteria for senior levels in Vietnam are most likely political (Bruynooghe, et al., 2009). Thus CPV membership remains a key element for career advancement in almost all occupations. It is a critical condition for advancement to senior administrative positions in governmental and public organisations, state owned enterprises and other institutions belonging to state sector (c/f www.cpv.org.vn, 2010). The selection criteria for any senior position does ask for demonstrated skills in management and ability to lead, potential candidates, but to be taken seriously, one has to gain their support by showing a commitment to the ideologies and ambitions of the government (under the control of the

CPV).

Other factors, apart from an accumulation of political capital, would work against the early application of psychological models to the Vietnamese contexts. These would include an uneven reproduction of social networks which may privilege one class above another, and allow some women to compete equally or better than some men in competition for a prestigious appointment. These include "patriarchal dividends" of inherited privileges (Connell, 2002), the structure of the field in which careers takes place (Kvasny, Trauth and Morgan, 2009) and the institutional factors, the "laws and policies of a geographic region" 
governing an "equality climate" (Trauth, 2011). Attempts to accommodate non-western factors and theories thus remain problematic.

Cross-cultural variations in women's career experiences then may ultimately rest on what can be discovered when apparently similar cases from one culture are placed alongside others in order to explain their differences. This has been done by Xian and Woodhams (2008). They follow Tu et al (2006) to ask the extent to which western theories of career management apply to seven women in management in the Chinese information technology (IT) industry. Tu et al found that Confucian values and collective beliefs of women as carers and homemakers override the attraction of the world of salaried employment. They conclude that existing theories of careers over-simplify the processes involved and do not hold up with the same magnitude when applied to women in the Chinese IT industry.

Two possible paths therefore appear from the emerging literature. More direct forms of comparative analysis can be used. But, following Cheung and Halpern's (2010) proposal of a shared "culture of gender," what other considerations are to be considered when studying western and non-western cases of women's careers? It would appear initially that separate analyses are required for cross-national studies where gender spaces are built from different traditions, historical circumstances and political and social conditions. Separations made between the two forms are obviously heuristic; each will feed into the other in practice. Finally, the practices as they are used in non-western and western contexts, their modus operandi, should ultimately be the bases for testing proposed models. It is into this state of play about the effects of comparative differences in model building, that we present our study of four women in elite positions in higher education in Vietnam. 


\section{The Study and Methods}

We drew on feminist standpoint epistemology to investigate the experiences of Vietnamese Rectors to establish a break from established Western theory on management and leadership. This was not because of deficiencies in these positions, but due more to a need to discover the bases on which standpoints could be established in Vietnamese history and present economic conditions. Feminist standpoint epistemology was used in this way to investigate the lives of the four women Rectors. This approach and not consciously setting out to test a theory would, we thought, minimise projecting data and theory from one into the other and avoid a potential to feed possible distortions. The study was designed to merge fine-grained analysis from interviews with research into religious philosophy, patriarchy and collectivist versus individualistic ideologies in Vietnam. Other research would be required to see if, or to what extent, these historically accumulated fought for conditions apply tangentially to Asian countries outside of Vietnam. Finally, there are limits to having only four respondents, but they represent over half the population of Women Rectors in Vietnam's public universities. The analysis may have been elaborated is family members and colleagues could have been interviewed, though this would have presented a separate set of methodological issues, especially when interviewing someone about those in a higher status to their own. To overcome these limits we have tried to present points of view within the social milieu in which the journeys took place.

The fieldwork for the study was carried out in two visits to Hanoi and Hochiminh City by one of the authors. One visit was mid-year in 2009 (during the New Year celebrations when respondents would have more available time) and a follow-up visit later that year. The aim was to understand how the lives and experiences of the four women who had become 
university Rectors could contribute to "alternative ways of thinking" (Smith, 2004:86) about women aiming "for the top" in higher education. This involved gaining the life histories of the women Rectors, aged from their mid-forties to sixty years. At the time of the interviews, all four women were married and had a maximum of two children. One woman had been in her first term for nearly two years while the other three others had completed their terms of office and returned to full time teaching job at their institutions - returning to one's faculty. This is a usual next step for former Rectors, both women and men in Vietnamese higher education. All spent most of their careers in the one institution and possessed strong institutional memories, experiences, thoughts, feelings and ideas that they expressed in their interviews.

An historical analysis of the Vietnamese context, Confucianism and the Doi Moi brought together a number of conditions (historical circumstances, social class, etc.) had been made into which the interviews and the life histories could be situated. Preparation for the interviews included analysis of the Rectors' resumes, provided on request, and of public documents. The interview questions were about family history, education, the processes leading to their appointment, their dealings with men and women with whom they worked and their operating styles as managers. The researcher also carried out a self-analysis to reflect on her own position, to prepare for the fieldwork on location in Vietnam after living in Australia for two years, to reflect on her circumstances with those of the Rectors and to monitor the influences of shared social, organisational and institutional contexts. Working with a small but elite group of women, practised in managing an interview process with the press or other media, places demands on the ability of the interviewer (Marshall and Rossman, 2006) who was from a lower social position. There was always the reminder that the balance of power was not always tilted mainly towards the interviewer. Interviews were recorded in 
Vietnamese and then translated into English. The analysis was more difficult than anticipated in terms of time, money and analysis.

In translation, a simple phrase in Vietnamese, for example, can have extensive and implicit meaning for a Vietnamese person who picks up on nuances. This same phrase may be interpreted as a single word or small phrase in English and thus lose all contextual and cultural meaning in English. Translation involved shifts from one language to the other to obtain a full interpretation of meanings embedded Vietnamese culture into English. This was made more difficult because Vietnamese people don't answer questions directly. Answers are given in terms of the collective value of an achievement so as to avoid an embarrassing public perception of being egotistical. This is not a problem in Vietnamese, but in translation the respondents appear to be talking around the topic for some time before going to the main idea. In reporting the research, phrases and words in Vietnamese were kept in the text in the final draft, original phrases and words of women participants in Vietnamese were often italicised as a footnote for each translation, all to remind readers that a translation had occurred.

Several provisional and broad categories were developed as apriori codes in both description and interpretatation of the interviews (Johnson and Christensen, 2003). Those codes were either kept as stated or were modified and checked against new data in the subsequent interviews. The categories identified included those relating to biographical data, career development, leadership practices, challenges and solution strategies and advice. Based on these apriori codes, interview transcriptions, observations, field notes, and documents followed a "categorical-content perspective" narrative method of data analysis (Lieblich, Mashiach and Zilber, 1998) to identify subcategories or inductive codes (Johnson and 
Christensen, 2003). The broad provisional categories identified were subsequently broken down into subcategories using line-by-line analyses of interview transcriptions supported by field notes, and other documents. Neuman (2006) suggests that these smaller, more concise segments give a more accurate analysis of the data. It allowed space to identify new categories that emerged in the data collection.

Finally, establishing the standpoints of the women rectors was not a matter of selection from their subjective experiences. They had to be situated within the historical conditions in which male/female relations had been established in Vietnam. This is now discussed.

\section{Women's' standpoints in the Vietnamese context}

The appointment of female university rectors makes history if only because their rise goes against what was thought to be possible in Vietnam. The individual herself can then seemingly be the person in control of her own fate and the sole author of this social marvel. But to use Marx's (1977: 10) well documented observation, they did not "make it as they please(d)... under self-selected circumstances, but under circumstances existing already, given and transmitted from the past." Their trajectories into a male domain of social space would remain purely subjective accounts if the standpoints of the Rectors are not related to the cultural and political conditions inherited from previous generations. To take Marx further, it can be said that male and female standpoints begin with basic social subsistence the essential labour required to eat, drink, be housed and clothed, so as to live from day to day. A sexual division of labour is thus initially formed and with it the allocation of women's duties as inside the home and men's work as being outdoors (c/f Bourdieu, 1979). Encompassing customs, traditions, religious beliefs, avenues to social honour and power relations are cemented in the division of males being in the outside world and women being 
confined to the home. These factors have to be explored to understand the standpoints of women who move between these spheres to secure a career.

\section{Confucianism}

Women's place in Vietnam is still much influenced by the patriarchal tenets of Confucianism. Introduced into Vietnam during the thousand years of Chinese occupation from $111 \mathrm{BC}$, it was later adopted as the official ideology of the Vietnamese feudal state. Confucian impacted on gender relations in Vietnam (Tuyet, 2005) and is now a foundation value in family life. To fulfil parents' expectations, children express their sincere thanks for their birthing. The family is patriarchal; men are the heads of households. It is patrilineal in that children bear the father's name and kinship and inheritance are in father's side. The family is patrilocal in that women become part of husband's family after marriage (Loi, 2003). In the Confucian ideology of ancestor worship men are afforded more social, economic and symbolic value for their role in maintenance of the family line, and their obligation to honour tradition. The relative low regard for women within Confucian ideology is evident in the saying, that "one hundred women are not worth a single part of man" (Bich, 2000). Vietnamese women, supposedly subordinate to men, are expected to practise the three Confucian obediences of: as daughters, to obey their fathers; as wives, to obey their husbands, and as widows to obey their eldest sons. Thus the roles of women in Vietnamese society are instituted to various degrees as obedient daughters, mothers and wives and as carers of parents, children and the house. As such, Confucian philosophy continues to exert its influence on women and remains strong even today.

\section{The Doi Moi}

In 1986 Vietnam initiated the Doi Moi (or renovation) as an initiative to create a "socialistoriented market economy". As state subsidies for childcare, family duties, health care and 
education were removed more women have been pressed into dual responsibilities, to earn money outside of the home and to work as usual within it (Vo, 2009). Although the Doi Moi gives women freedom in choosing jobs, especially in the newly developed private sectors, most employers - even in the state sector - avoid recruiting women because of the potential financial loss associated with child bearing and child rearing (Vo \& Strachan, 2008). Women have therefore to work harder to compete with men in the workplace to secure their positions but at the same time doing their best at home to maintain family happiness. Vietnamese women are both the winners and the losers in the market economy in Vietnam (Anh and Hung 2000). In this context, how do the Vietnamese women's careers advance in comparison with those of men?

For example, the timing and planning a career is another barrier.as the compulsory retirement age of fifty five for women in all state public sectors in Vietnam. Men can work until sixty. Thus women seeking promotion have to prepare five years earlier than men, which is a double challenge for Vietnamese women who are passed over for opportunities in their career development. This is evident in the following statement from Mai's (2007) research.

I am 30 years old and just completing my Masters degree. There is special political training for senior civil servants, which is an important condition for civil servants to be promoted to a leadership position. The criteria for participants are men under 41 and women under 36 years old with a certain salary level (3.6). In order to get this level, I would need 8 years more. By this time I will be 38 years old and will no longer be eligible to participate in the training. If I were a man, I would still be eligible until I was 40 . It is so unfair. 
I have worked so hard but already my chances are over before I ever really began!

Thus Vietnamese women may be automatically cut off from promotion opportunities and their advancement to senior positions is put on an early hold in comparison with men (Vo, 2009:233). It is on this social fact of timing being of crucial importance that the process of becoming a Rector is now discussed.

\section{Becoming and being women Rectors in Vietnam}

Where much of the literature focuses almost exclusively on what women do once they assume a leadership position, we suggest seeing the journey in two parts. A woman in Vietnamese higher education must prove herself as worthy to take the path for which there few female precedents for becoming a Rector. Once appointed, the selected woman must prove herself as a manager in a public male dominated arena. Some of the characteristics of the female Rectors in each domain are now sketched.

The usual approaches to the presentation of life histories were not suitable because the Rectors could be easily identified, which could cause some embarrassment and loss of public face by attributing direct quotes to them as individuals. As an alternative, an amalgam was created to tease out common points of reference have been joined when making statements about their journeys or to represent an ideal type of the characteristics of the Rectors in general terms. This is the case the composite pictures of becoming a female Rector shown in this section.

The Rectors have had to work on both sides of the gender line. They must, it bears repeating, prove themselves worthy in each domain: in the selection process of becoming a Rector and 
then to display proof of her ability to take command in the university in which they have been appointed.

Two phases were identified in each woman's life trajectory. The first was in becoming Rectors factors in their biography, family and education in Vietnam and overseas were needed to begin the journey. The second phase, involved being the first Rector in their university.

\section{Becoming a Woman Rector in a public university}

In Becoming a Rector, a woman is most likely born and raised in Vietnam in a middle or upper class, intellectual two-parent family. She is probably is the first or middle girl but not the only child in her family. Currently somewhere between her middle forties and late fifties, she lives with her husband and is likely to have had one or two children. She is expected to have a university degree in Vietnam plus an overseas doctorate. The woman Rector usually starts her career in a public university in Vietnam as a teacher and will remain at this university until retirement. She is influenced and supported by her parents, her husband, family members, male predecessors, female university lecturers, supervisors and colleagues. Although not likely to plan her career she is promoted to several responsible academic administrative positions. The Rector will be appointed as an internal candidate in her mid-forties, much earlier than her peers. Luck plays a part in her career advancement.

As is evident in this ideal typification, to become the first Rector of a university in Vietnam a woman must have accumulated a certain amount of cultural and social capital. Her capital, 
family and other resources must peak at the time of the Doi Moi and must be around her midforties to be eligible to make use of the opportunities available at that time. These initial circumstances help to place women on a male dominated path to the top parts of higher education where there is no female equivalent. Their reflection on setting foot on a path not open to other Vietnamese women becomes a point from which new knowledge can be built. If planning to be a Rector means taking a route not travelled by others, the women Rectors will naturally see their ascension as "unintentional," "accidental" and due in part to "luck," (e.g. I was lucky to be given continuing educational opportunities; I was bestowed the academic titles earlier, so I was appointed at a relatively early age."). Finally, in terms of luck, a woman must be on staff in one of over one hundred public universities and colleges where senior staff agree to put forward a woman for selection as a Rector.

Their advantage is to be born in a family where Confucian son-favoured practices were not supported, where "we knew we were going to university," where being "trained overseas, ' returning with $\mathrm{PhDs}$ helped "develop my academic ability but also to learn how to organise and work methodically". Coupled with this, but not in all cases, there are family role models: a grandparent who studied at the Sorbonne; coming from a family with national prestige in an area. Each woman had to prove themselves as good teachers and build "the ideal image of a female staff member... (doing an) impressive amount of hard work in the faculty."

It is thought that behind a successful man is a selfless woman, but this reverses applies for them. Besides influential parents laying a foundation for their later success, the role of their husbands was critical. Their spouses appear unthreatened in reversing normative roles that put their wives in the public spotlight and give women a high status. For these men "the 
wife's accomplishments and the resources she brought to the marriage were defined as collective assets to the family instead of threats in a power struggle" (Cheung \& Halpern, 2010, p. 187). Thus family history, the backing of parents and husbands, long-term educational investments, community and professional coupled with the talents they brought to bear on the job, all work as a support system.

The process of mentoring, so often discussed as a means for women to become upwardly mobile in Western countries, is often not available in the Confucian and patriarchal system of seniority in Vietnam. Most of their peers were men, and none of the Rectors had official mentors, although some encouragement to apply for promotion is mentioned. As each was the first woman to be put forward as a Rector in their university, they would have had to avoid a sceptical view taken in Southeast Asian countries, of women who initiate professional contact with male colleagues and seniors. Men can build individual networks to further a career. In contrast, a woman who becomes a Rector has to respond, or has to be seen as responding to and fulfilling collective needs. For example, it was only with "explanation and encouragement, I started to think that I could do this job and I moved forward." And again, "I never thought I would end my professional career with the position of the Director. My aim was (to pursue my specialisation as a career). But I couldn't refuse the encouragements of people... who trusted in me."

From this description of the circumstances of becoming Rectors of universities in Vietnam we now turn the processes of women being a woman Rector.

\section{Being a Woman Rector in a public university}

After her appointment the Rector experiences some gender stereotyping and challenges in the workplace based on cultural and social expectations about 
femininity in the patriarchal Vietnamese society. She tends not to dwell on these claims; her strategy is to rise above them. She receives support and help from her husband to balance her family life and career. Rather than adhering to a single style of leadership, she combines her male/female experiences through delegation being inclusive, and collaborative promoting participation, information sharing and team-building. She strengthens her leadership and professional skills by being active in professional, social and women's organisations. During her career the woman Rector works hard, is at ease in her position and is satisfied with her achievements.

Just as no paths existed for each woman prior to her appointment, no operating models were available to them afterwards, aside from those set by the men who preceded them. A fresh set of interactions came into play for both the new Rector, who herself has only worked with male Rectors and for her staff, male and female, who have only dealt with men in the position. Since the woman cannot "be a man," as is the historical expectation of what a Rector has always been, a pragmatic option is to employ the dual view women have of male/female relationships. As a woman in a previously male-only domain, her management strategy has to combine traditional Confucian male traits of being decisive with traditional female traits of being collaborative and nurturing.

“...the effective woman Rector is a person who understands and combines both male and female traits in her management position...The image of university Rectors in Vietnam is still based on male standards. It's a trap when a woman Rector tries to model strictly male traits in her position but she is more effective when using them flexibly in different situations". 
Where the Rectors respected their staff, invited them into decision-making processes, they made the final decision in a directive way; even when others were not satisfied. For example, "I appreciated my staff's ideas but I was the person who finally made the decision after considering all positive thoughts. Sometimes, I had to convince them to follow my decisions but it did not mean a compromise. They had to understand me, my role and my style.". In their role the women Rectors did not transform themselves completely into an image of what a feminine university Rector might look like. In their situation, a standpoint was taken, of being a Rector who met previous expectations and incorporating a female dimension to their operating style. Outside of being a Rector, there remains a woman's responsibility to conform to the three Confucian obediences. Like other working women in Vietnam they face the double social expectations to work creatively, to raise children well and to build happy families; to be good at national tasks and good at household tasks. But with regard to family and career balance, the women Rectors seemed, in general, not to be as worried or as entangled in this issue managing to meet the family responsibilities expected of them.

They faced sociocultural situations commonly encountered by career women in the Vietnamese context as described by Mai (2007). In the early stages of taking up the position, each of the women spoke of colleagues and other university staff placing them under suspicion. This can be expected when making tough decisions, where others watch to see how a woman handles the pressures of the top job. As such, each woman faced the incongruity between her role as a manager and the social expectations on her as a woman. Some staff and colleagues saw them as exhibiting male traits, of being "too ambitious", "aggressive" and "forceful". Like other Vietnamese women counterparts and women in academia in some Asian countries, some Rectors were the centre of the negative rumours about their family with some being sceptical about the basis of their relationships with male colleagues. 
While Mai (2007) indicates that women's personal insecurities could prevent Vietnamese women from participating in university management, the Rectors saw much of what they had to deal with as being generated from within the organisation itself; not from within them as people. In general, positive self-perceptions, gained from breaking through the constraints career on advancement for Vietnamese women, made it possible for them to rise above rumours to work hard to move their universities forward - and to do this as women treading this path for the first time.

\section{Women Rectors: coexisting with Vietnamese history and context}

Looking across the four cases, some aspects of their experience were supported by the Western literature but others that were not and could be said to have been generated from within the distinctiveness of the context of Vietnam. Literature and research on successful women leaders and their experiences has been inclined to focus on the characteristics of women leaders after they have arrived, rather than on the foundation and background from which those women originated (Madsen, 2007). For Barry (2009), many factors need to be drawn together to understand women's career advancement. Historical circumstances, social class, personal background, current context, sociocultural conditions, educational attainment and professional development, must all be included. The similarities in the four women Rectors' career paths are due in part to the uniqueness of the political and economic conditions of Vietnam, where they were born, grew up, attended schools and universities, married and entered and developed careers in higher education. Their position and standpoints should be seen as one of coexistence with a place and time, where breaking with tradition in some way became a possibility for some women. The standpoints of these women 
are not those of women in Western contexts whose rights to hold positions of power has been placed more openly on the public agenda. Instead, the Vietnamese strategy is to continue to live as women within a domain historically designed for men, to see, assess and work on situations from an understanding of two standpoints. Further research could show this latter situation of coexistence to be analogous with women's "double consciousness", or "dual vision”, as reported by Brooks (2007) and others within feminist standpoint epistemology. The women who have become Rectors have benefitted in the circumstances of the era in which social and economic change occurred in Vietnam. As the sociologist Max Weber observed, the healthier the economic situation, the higher the status and the greater one's power, the better one's life chances will be. Similarly, as Astin and Leland (1991:40) state, "our women leaders are the progeny of their historical and social periods." Being from elite intellectual families, these women were freed from environments where not succeeding in education was not an option. Being raised in the North during the Vietnam War, they benefitted from the policy of sending academic students abroad, begun in the 1950s and 1960s.

Where the Doi Moi brought both favourable and negative consequence for Vietnamese women, it provided a window of opportunity for a select few with the capital of overseas degrees and doctorates which made them stand out. Their chances of entering a male domain were thus higher than in previous times where patriarchal Confucianism held more sway.

These historical, social, political, economic movements in Vietnam formed a special context that helped develop their identities as women with a role to play in Vietnamese society and in their careers in higher education. Who these women are today is partly due to the environments and opportunities experienced over the course of their lives. 


\section{Implications for theory: reflecting on women in higher education}

In the history of higher education in Vietnam only seven women have reached the highest level as head or Rector of a public university. This paper has described the processes through which four of these women rose to the elite status of head of a university. Our main contribution has been is demonstrating how becoming and being a Rector are two separate parts of the journey. Within our formulation, each woman had to be in the right place with the capitals - social, cultural, family and political - that brought them into a position of being selected to undertake the journey. Along with this, they had to be there at the right time, when the economic changes of the Doi Moi provided some possibilities for a few women at that historical juncture. The theoretical implications of becoming a women in charge of a university in Vietnamese higher education require more analysis in the Vietnamese context before being taken into wider generalisations. Alternatively, being at the top was seen to rest on melding feminine ways of managing in a mainly male context. Here the model based on a culture of gender and transformative management styles would perhaps relate to models such as those by Cheung and Halpern (2010). The unevenness of impact of western theory on non-western problems of women's careers outlined by Tui, et al (2006) and Xian and Woodhams (2008) and in our research might benefit from a closer application of the "patriarchal dividends" of inherited privileges researched by Connell (2002) and the institutional factors, governing an "equality climate" in the laws of different regions suggested by Trauth (2011). From this start further questions can be proposed. Are the journeys of these Vietnamese women similar or different to others in the research literature on other nations? Is it the cases that some established concepts will not translate as well or as easily as anticipated into other cultures and countries? Do our existing models comfortably 
contain the Asian problems at hand (Atlatas, 2006), or should they be extended or placed in abeyance for a while?

On this note Bulbeck (1998: 55-56), offers a guide to writing about women beyond the west. To do so is to avoid placing other women, "India or Vietnam," on one side of a dichotomy with western women on the opposite side. Rather, it is more to do with the return benefits from "how we see the position of Anglophone white women differently as a result of what women from these nations write"; for each to see each other with more understanding, and as a potential source of strength. This means "walking a tightrope between similarity and difference."

\section{References}

Alatas, S. (2006). Alternative Discourses in Asian Social Science: Responses to Eurocentrism. Sage.

Anh, T. and Hung, L. (2000). Women and Doi Moi in Vietnam. Hanoi: Women's Publishing House.

Astin, H. and Leland, C. (1991). Women of influence, women of vision: a cross-generational study of leaders and social change. San Francisco: Jossey-Bass.

Barry, T. (2009). Womens' career pathways to the college presidency: A study of women in two-year technical colleges. Retrieved from Dissertations \& Theses (Publication No. AAT 304918876). August 2, 2010.

Bich, N. (2000). Gender equity in higher education in Vietnam: the case study of women faculty in Vietnam National University - Hanoi. University of Oregon, Oregon. 
Bourdieu, P. (1979) Algeria 1960: The Disenchantment of the World: The Sense of Honour: The Kabyle House or the World Reversed: Essays, Cambridge Univ Press.

Brooks, A. (2007). Feminist Standpoint Epistemology: Building Knowledge and Empowerment through Women's Lived Experience. In S. N. Hesse-Biber \& P. Leavy (Eds.), Feminist Research Practice (pp. 53-82). London: Sage.

Broadbridge, Adelina and Hearn, Jeff (2008)Gender and Management: New Directions in Research and Continuing Patterns in Practice British Journal of Management, Vol. 19, S38S49.

Bruynooghe, S. P., Faingold, I., Firmalo, T. Q., Futrell, A. E., Kent, J. A., \& Mukherjee, R. (2009). Implementation of Civil Service Legislation in Vietnam: Strengthening Elements of a Position-Based System. New Jersey, USA: Princeton University.

Bulbeck, C. (1998) Re-orienting Western Feminisms: Women's Diversity in a Postcolonial World. Cambridge: Cambridge University Press.

Cheung, F. M., \& Halpern, D. F. (2010). Women at the Top: Powerful Leaders Define Success as Work + Family in a Culture of Gender. American Psychologist, 65(3), 182-193. Connell, RW. 2002. Gender. Cambridge, Polity Press; Malden, Blackwell Publishers. Author. (2011). Journeys to the top: the case of women Rectors at selected public universities in Vietnam. A thesis Submitted in fulfilment of the requirements of the degree of Doctor of Education Griffith University.

Jogulu, U and Wood, W. (2011) "Women managers' career progression: an Asia Pacific perspective", Gender in Management: An International Journal, Vol. 26 Iss: 8 pp. 590 - 603. 
Johnson, B., \& Christensen, L. (2003). Educational research: Quantitative, qualitative, and mixed approaches. Boston, MA: Pearson Education Inc.

(Kvasny, Trauth and Morgan, 2009)

Lieblich, A., Mashiach, R. T., \& Zilber, T. (1998). Narrative Research: Reading, Analysis, and Interpretation. Thousand Oaks: SAGE Publications, Inc.

Loi, D. (2003). Perceived influences of the family on the academic achievement of Vietnamese women: four case studies. University of Akron.

Lukács, G. (1971). Reification and the Consciousness of the Proletariat. In R.Livingstone (Ed.), History and Class Consciousness. Cambridge, Massachusetts: The MIT Press.

Luke, C. (2001). Globalization and women in academia: North/West-South/East. Mahwah, N.J.: L. Erlbaum Associates.

Madsen, S. (2007). Women University Presidents: Career Paths and Educational Backgrounds. Academic leadership the online journal, 5(1).

Mai, T. (2007). Cơ sở lý luận và thực tiễn của các giải pháp tăng cường vai trò đội ngũ cán bộ nữ trong hoạt động quản lý nhà trường đại học (Theoretical and practical bases to enhance women's roles in university management: theory and practice). Hanoi National univerisy, Hanoi.

Marshall, C., \& Rossman, G. B. (2006). Designing qualitative research (4th ed.): Thousand Oaks, CA: Sage. Marx, K. (1977) The Eighteenth Brumair of Louis Bonaparte. New York: International Publishers. 
Narayan, U. (2004). The Project of Feminist Epistemology: Perspectives from a Nonwestern Feminist. In S.Harding (Ed.), The Feminist Standpoint Theory Reader: Intellectual and Political Controversies (pp. 213-224). New York: Routledge.

Neuman, W. L. (2006). Social research methods: Qualitative and quantitative approaches (6th ed.). Cambridge: Pearson International.

Pham Hanh Sam (2011) "Women-in-leadership-and-management-in-Viet-Nam” http://english.tapchicongsan.org.vn/Home/Theory-and-Reality/2011/264/Women-inleadership-and-management-in-Viet-Nam.aspx (last retrieved 9:18' 26/12/2011).

Smith, D. (2004). Women's perspective as a radical critique of sociology. In S. Harding (Ed.), The Feminist Standpoint Theory Reader: Intellectual and Political Controversies (pp. 21-33). New York: Routledge.

Trauth, E. (2011) "What Can We Learn from Gender Research? Seven Lessons for Business Research Methods" The Electronic Journal of Business Research Methods Volume 9 Issue 1 (pp 1-9.

Tsang, A. Y., \& Zhang, L. (2006). Women Leaders in Universities in Hong Kong \& China: Challenges, Tensions, Dilemmas and Opportunities. Retrieved 27/9/2007, from www.wexdev.curtin.edu.au/local/docs/2006conference/Wed0830.ppt

Tu, H. Forret, M. and Sullivan, S. (2006), "Careers in a non-western context: an exploratory empirical investigation of factors related to the career success of Chinese managers", Career Development International, Vol. 11 No. 7, pp. 580-93.

Tuyet, L. T. N. (Ed.). (2005). Images of Vietnamese Women in the 21st Century. Hà Nội Thế Giới Publisher. 
Vo, A. N. (2009). The changing face of women managers in Vietnam In C. Rowley \& V. Yukongdi (Eds.), The Changing face of women managers in Asia (pp. 224-244). London and New York Routledge.

Vo, A. N., \& Strachan, G. (2008). Gender equity in a transforming economy. Paper presented at the Ninth International women in Asia conference.

Yáñez, J. and Moreno, S. (2008),"Women leaders as agents of change in higher education organizations", Gender in Management: An International Journal, Vol. 23 Iss: 2 pp. 86 - 102 Yin, R. K. (2003). Case study research: design and methods. CA: Sage publications, Inc. 